\title{
Effect of Thermal Modification on Mechanical Properties of Canadian White Birch (Betula papyrifera)
}

\author{
S. Lekounougou, D. Kocaefe*, N. Oumarou, Y. Kocaefe, S. Poncsak \\ Department of Applied Sciences, University of Quebec at Chicoutimi, \\ 555 Blvd. de l’Université, Chicoutimi, G7H2B1, QC, Canada \\ * Duygu_Kocaefe@uqac.ca, phone: (418)-545 5011 ext 5215 Fax: (418)-545-5012
}

\begin{abstract}
Wood is a renewable material widely used in the construction industry. However, it is susceptible to fungal degradation. Several chemical products have been developed to improve its durability, but the toxicity of some of these products limits their use. One alternative to chemical treatment is thermal modification of wood. This method improves the dimensional stability of wood and reduces its susceptibility to decay. The impact of different parameters (maximum temperature, heating rate, holding time, and gas moisture content) of thermal modification on the mechanical properties of Betula papyrifera was studied in a prototype furnace. The results show a marked decrease in the modulus of rupture with increasing temperature while the modulus of elasticity does not seem to be affected. The hardness increases with maximum modification temperature, and in the absence of moisture in gas, and there is an improvement of the dimensional stability after thermal modification.
\end{abstract}

\section{Keywords}

Bending strength, dimensional stability, hardness, thermal modification, heat treatment, modulus of elasticity, white birch 


\section{INTRODUCTION}

Wood is a renewable material used in several fields such as buildings and in paper pulp manufacturing. The economic impact of timber products is therefore considerable. One third of the circumpolar boreal forest of the Northern Hemisphere lies within the Canadian borders and birch is one of the principle species of this forest. Therefore, adding value to this species is very important for the economy of Quebec and Canada. Nevertheless, in recent decades, there has clearly been a declining production of high quality or more specifically of durable timber from the currently available forests. As a consequence of the introduction of increasingly restrictive regulations by governments for the protection of the environment, the availability of this material will decline even further and therefore the use of less durable timber species needs to be considered. To that end, technologies for improving timber dimensional stability, bending strength, and durability are indispensable and widely used in Europe and North America. In Quebec, a market analysis, carried out by the biggest private and non-profit research institute on wood in the world, FPInnovations (2010), showed that there is a market for thermally-modified wood in Canada and North America.

Thermally-modified wood can be used in various applications such as interior and exterior wall panels, different wood work, furniture and other value-added wood products. In Quebec, there are 1700 small enterprises which can use thermally-modified wood in cabinet, furniture and other carpentry work, doors and windows, sidings, pre-fabricated houses, beams, roofs etc.

In the field of wood treatment, there are several existing technologies such as impregnation of pesticides, densification, resin impregnation, and chemical modification of the cell wall components (Schultz and Nicholas 2002, Mabicka et al. 2005). The use of traditional wood preservatives such as chromated copper arsenate (CCA) or creosote is increasingly under control, since questions regarding the environmental acceptability of biocide products generally became more important due to environmental restrictions. Generally, the commonly used wood preservatives (creosote, chromated copper, and arsenate salts) are rather poisonous for humans and animals. Allternative preservatives such as triazoles have been developed but exhibit reduced effectiveness thereby 
limiting their application (Hingston et al. 2001).

One of the non-biocidal alternatives to the chemical treatments is thermal modification of wood. Research has been carried out since the 1950's on the thermal modification of wood, using relatively high temperatures between $230-260^{\circ} \mathrm{C}$. This results in permanent chemical changes to the substrate and hence is termed a thermal modification (Seborg et al.1953, Stamm 1964, Bourgeois and Guyonnet 1988, Hill 2006). This method enables the transformation of wood which is susceptible to biological attack into wood products of consistent quality. The foremost advantages of thermally-modified wood are its higher resistance to different types of biodegradation and improved dimensional stability without the use of chemicals compared to untreated wood. However, the mechanical properties of wood are adversely affected. Therefore it is important to minimize the loss in mechanical properties during thermal modification. Degradation of hemicellulose during thermal modification decreases the bending strength. Thermal degradation disrupts the load sharing capacity of the lignin-hemicellulose matrix in which the cellulose microfibrils are embedded (Levan et al. 1990). In the literature it is known that hemicellulose is the most thermo-chemically sensitive components of wood (De groot et al. 1988, Bourgois and Guyonnet 1988). Wood polymer degradation in cell walls was found to be the main contributors to mechanical properties by various researchers (Akyildiz et al. 2009, Ates et al. 2009, Nazerian et al. 2010). Kocaefe et al. (2008) carried out a study with thermally-modified birch and aspen using IGC (Inverse gas chromatography) and FTIR (Fourier transform infrared spectroscopy). They reported that the loss of mechanical properties is the result of degradation of hemicellulose and to a lesser extent a consequence of lignin degradation and crystallization of cellulose. Birch was affected more than aspen. It was also found that the mechanical properties decreased sharply above $200^{\circ} \mathrm{C}$ as the polysaccharide content of wood decreased. This study was carried out with small birch samples using a thermogravimetric analyser in contrast to the present study which was carried out in a semiindustrial scale furnace with standard wood boards. When small samples are used the mechanical tests are also carried out with small samples which do not correspond to sample sizes recommended 
by ASTM standards. These experiments only give the trends. However, to our knowledge, there is no study reporting the actual values, resulting from the effect of thermal modification on the mechanical properties of birch under different conditions. Recently, interest in thermal modification has been renewed. Five main different commercial technologies have emerged: Thermowood in Finland, Plato Wood in Holland, OHT in Germany (OHT- Oil Heat Treatment), and two in France (Bois Perdure and Retification); new thermal modification processes are also emerging in other countries such as Denmark (WTT) and Austria (Huber Holz). The main differences between these methods are based on the materials used (wood species, fresh or dried wood, moisture content, dimensions) and the applied process conditions (one or two process stages, wet or dry process, heating medium, air or nitrogen as inert gas, heating and cooling rates) (Militz 2002).

In this study, the thermal modification of North American Betula papyrifera was investigated under different conditions using the Perdure technology in the prototype furnace at the University of Quebec at Chicoutimi (UQAC), and the effects of the modification parameters on the mechanical properties of white birch as well as dimensional stability are discussed and presented in this article.

\section{MATERIALS AND TEST PROCEDURES}

Pre-dried (moisture content 5-17\%) Canadian white birch wood (Betula papyrifera) with dimensions of $0.045 \mathrm{~m} \times 0.015 \mathrm{~m} \times 2.44 \mathrm{~m}$ in tangential, radial, and longitudinal directions, respectively, were prepared and planed to final dimensions . Wood specimens came from a local sawmill in Saguenay-Lac-St-Jean (Quebec, Canada). All test specimens were conditioned in a climate chamber for 4 weeks at $65 \% \pm 3 \%$ relative humidity and $23^{\circ} \mathrm{C} \pm 1{ }^{\circ} \mathrm{C}$ prior to testing.

\section{Thermal Modification}

The thermal modification of white birch was carried out in the prototype furnace of UQAC. This technology is a subject of a patent application (Kocaefe and Kocaefe, 2008). In this furnace, propane is burnt and the wood is modified under a non-oxidizing medium composed of hot 
combustion gases $\left(\mathrm{CO}_{2}\right.$ and $\left.\mathrm{H}_{2} \mathrm{O}\right)$. It is heated to the maximum modification temperature and this temperature is kept constant for a desired time period which is called the holding time. After the modification, wood is cooled with a water spray. The thermal modification parameters studied were the maximum modification temperature, the heating rate, the holding time (exposure time) at the maximum modification temperature, and the gas moisture content. The conditions for the experimental trials are given in Table 1. During the experiments one parameter at a time was changed. Other parameters were kept the same as those of the base condition.

\section{Measurement of the mechanical properties}

Three-point bending (MOR, MOE), hardness, and dimensional stability tests were carried out in order to determine the effect of thermal modification parameters on the mechanical properties of untreated and thermally-modified wood under different conditions, and the results were compared. MTS ALLIANCE RT 100 Universal Mechanical Test Machine was used for the measurements.

\section{Test 1: Effect of thermal modification on bending strength}

Three- point static bending tests were carried out according to the ASTM D-143-8 standard (ASTM International 2004). The size of the samples was 25.4 x 25.4 x $406.4 \mathrm{~mm}$. The moving head speed and the span length were $1.3 \times 10^{-3} \mathrm{~m} / \mathrm{min}$ and $0.1524 \mathrm{~m}$, respectively. The obtained load deformation data were analyzed to determine the modulus of rupture (MOR) and the modulus of elasticity (MOE). Tests were repeated fourteen times for each treatment condition.

\section{Test 2: Effect of thermal modification on hardness}

Penetration hardness tests were performed in accordance with the ASTM D-1324-83 standard (ASTM International 2004). A maximum force of $400 \mathrm{~N}$ was used during the tests. Ten wood specimens with dimensions 25.4 x 76.2 x $152.4 \mathrm{~mm}$ were tested for each set of parameter. The diameter of the ball was $12.7 \mathrm{~mm}$ and the penetration rate was $6 \times 10^{-3} \mathrm{~m} / \mathrm{min}$. Tests were repeated nine times on the radial, tangential, and longitudinal faces for each sample. 
Test 3: Effect of thermal modification on dimensional stability

The tests to determine dimensional changes were carried out on three or five specimens with dimensions 152.4 x 152.4 x 25.4 mm. ASTM D-1037-105 standard (ASTM International 2004) was followed for dimensional stability tests. Before the tests, specimens were weighed with SARTORIUS GW7201 analytic balance (precision $\pm 0.1 \mathrm{~g}$ ), and their average dimensions were measured in radial, tangential, and longitudinal directions. During the tests, the samples were kept immersed in distilled water for $24 \mathrm{~h}$. The water temperature was $20 \pm 1^{\circ} \mathrm{C}$. Afterwards, their weights and dimensions were again measured. Moisture content (MC) as well as swelling (SW) in tangential, radial, and long itudinal directions were measured. Swelling (SW) for a given specimen was calculated as:

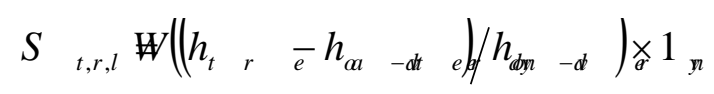

where $\mathrm{h}_{\text {treated }}$ is the dimension of the treated sample in $\mathrm{mm}$; and $\mathrm{h}_{\text {oven-dry }}$ is the dimension of the ovendry sample in $\mathrm{mm}$.

\section{RESULTS OF TESTS AND DISCUSSION}

\section{Effect of thermal modification on bending strength}

The data in Figures 1a and 2a show the impact of maximum modification temperature on the modulus of rupture (MOR) and the modulus of elasticity (MOE). These results show that the effect of temperature on MOR is more significant than its effects on MOE. In Figure 2a a slight decrease of the MOE is seen whereas the MOR decreases significantly with increasing temperature under the conditions of the study. Similar findings were reported in the literature with different wood species (Bekhta and Niemz 2003, Kocaefe et al. 2007). The bending strength loss might be due to hemicellulose degradation (Kaas et al. 1970, Levan et al. 1990, Winandy and Lobow 2001, Kocaefe et al. 2008). Indeed, the main polymeric components of the cell wall (cellulose, hemicellulose, and 
lignin) are linked by covalent and hydrogen intrapolymer bonds (Winandy and Rowell 1984) and they contribute in different degrees to the strength of wood.

Figure1b-d and Figure 2b-d show the influence of holding time at maximum temperatures, heating rates, and gas moisture contents on MOR and MOE, respectively. Overall, MOR of the thermallymodified samples is lower than that of untreated samples (Fig 1b-d). Comparison with the MOE values of the untreated wood with those of thermally-modified wood shows that a thermal modification at low heating rate $\left(10^{\circ} \mathrm{C} / \mathrm{h}\right)$ increases $\mathrm{MOE}$ of wood (Fig 2c). Also, thermal modification in the absence of gas moisture content can cause an increase in MOE compared to that of untreated wood (Fig 2d).

MOR does not seem to be affected by holding time after modification for the thermally-modified wood (Fig.1b) whereas MOE of thermally-modified wood increases with holding time (Fig. 2b).

There is only a slight difference in MOR values at heating rates of $10^{\circ} \mathrm{C} / \mathrm{h}$ and $15^{\circ} \mathrm{C} / \mathrm{h}$ (Fig. 1c) whereas MOE decreases with increasing heating rate (Fig. 2c).

The effect of gas moisture content on MOR and MOE is shown in Figures 1d and 2d. As shown in these figures, the MOR decreases with or without added gas moisture content (see Fig1d) when compared with the MOR of untreated wood, but the decrease is more significant in the presence of gas moisture content. MOE of thermally-modified samples without gas moisture content is higher than those of untreated control samples and the thermally-modified samples in the presence of gas moisture content (Fig. 2d).

Degradation of hemicellulose disrupts the load-sharing capacity of the lignin-hemicellulose matrix and an increase of the relative amount of crystalline cellulose could contribute to the modification of the MOE. Furthermore, the increase in cross-linking of the lignin network probably also affects MOE since it is expected that an increased cross-linking upgrades the rigid structure around the cellulose microfibrils. The thermally-modified wood is less hygroscopic than untreated wood (it contains less bound water in the cell wall), which can also affect its MOE (Levan et al. 1990, Hill 2006). 


\section{Effect of thermal modification on birch hardness}

Figures 3 a-d present the impact of maximum thermal modification temperature, holding time, heating rate, and gas moisture content on the white birch hardness. The results show that the birch hardness in longitudinal direction first increases then continues to increase after a slight decrease at $205^{\circ} \mathrm{C}$ with the maximum temperature compared with that of untreated wood under the conditions used in this study (Fig. 3a). In the radial and tangential directions, the birch hardness is not significantly affected by the maximum modification temperature. The increase of the hardness in the longitudinal direction might be because of the increase in the amount of the highly ordered crystalline cellulose due to the crystallization of amorphous cellulose supporting the wood structure. The hardness of white birch increases in the longitudinal direction with holding time as shown in Figure 3b. In the radial and tangential directions, there is practically no effect of holding time on the hardness.

Figure 3c presents the effect of heating rate on the birch hardness. The results show that the effect of heating rate on hardness is not significant in the radial and tangential directions. In the longitudinal direction, while a slower heating rate seems to increase the hardness of white birch, there is a clear decrease when the heating rate further increases.

The results presented in Figure 3d show the impact of the presence and absence of moisture in the gas upon wood hardness in the three directions (radial, tangential, and longitudinal). Certainly, in the absence of gas moisture during modification, there is an increase in the white birch hardness in all three directions. It is well known that bound water strongly affects the strength properties of wood. Increase in bound water content reduces hydrogen bonding between the organic polymers of the cell wall, and consequently decreases the strength properties of wood since strength is related to covalent as well as to hydrogen intrapolymer bonds (Winandy and Rowell 1984). 
As it can be seen from Figure 4, dimensional stability is significantly improved with thermal modification. The percentage dimensional change of thermally-modified wood is always lower compared to that of untreated wood in all three dimensions under the conditions used during this study. The temperature of thermal modification considerably affects the dimensional stability of wood when compared to that of untreated wood (Fig. 4a). However, above $195^{\circ} \mathrm{C}$, any further increase in temperature does not significantly affect the dimensional stability up to the final temperature $\left(205^{\circ} \mathrm{C}\right)$. A slight decrease in percentage dimensional change is observed when the sample is further heated to $215^{\circ} \mathrm{C}$. The change is most significant in the radial direction. It seems that the birch already has good dimensional stability in tangential and longitudinal directions before the modification ( $<1.5 \%$ change). There is a slight improvement in dimensional stability with temperature of modification.

Increasing the holding time increases the dimensional stability (Figure $4 \mathrm{~b}$ ). Too high heating rates seem to be unfavourable (Figure 4c). The presence of moisture in the gas does not seem to affect dimensional stability in the radial direction whereas it is slightly affected in the tangential and axial directions (Figure 4d).

This phenomenon might be due to the depolymerization of the carbohydrates and especially hemicellulose, causing a reduction in the total amount of hydroxyl groups, including the free hydroxyl groups (Sandland 1998), and the increase of the crystalline cellulose proportion, in which the hydroxyl groups are not easily accessible to water molecules (Winandy and Rowell 1984; Kocaefe et al. 2008). The cross-linking of the lignin network might also hinder the accessibility of free hydroxyl groups to water (Pizzi et al. 1994). The heating rate and gas moisture content do not appear to affect the wood dimensional stability in all three directions (Fig. 4c-d). The holding time has a slight effect in the longitudinal direction with a better dimensional stability for the holding time of three hours compared to that of one hour holding time (Fig. 4b). 


\section{CONCLUSION}

The current study shows that thermal modification clearly affects the mechanical properties and dimensional stability of white birch. The MOR decreases markedly with increasing temperature. In some cases, an increase of the modulus of elasticity during the bending test has been observed after modification. The maximum modification temperature has a stronger effect on the modulus of rupture than on the modulus of elasticity.

The heating rate, holding time and gas moisture content do not significantly affect the mechanical properties of white birch under the conditions used in this study. Modification of the main wood polymer components appears to manifest the effects of thermal modification through mechanical properties. The possible effects of degradation and modification of hemicellulose, crystallization of amorphous cellulose, and polycondensation reactions of lignin can explain the decrease of mechanical proprieties during thermal modification.

The results show that an increase in modification temperature leads to an increase in hardness of white birch in longitudinal direction. In the absence of gas moisture content, there is an increase in the hardness of white birch in radial, tangential, and longitudinal directions. A longer modification time increases the hardness of white birch in the longitudinal direction. Slower heating rate seems to increase the hardness of birch in the longitudinal direction.

Significant improvement in dimensional stability is also observed in all three directions following the thermal modification.

\section{ACKNOWLEDGEMENTS}

The authors would like to acknowledge the financial contributions of NSERC (Natural Sciences and Engineering Research Council), UQAC (University of Quebec at Chicoutimi) and FUQAC (Foundation of the University of Quebec at Chicoutimi). 


\section{REFERENCES}

ASTM International. (edited). 2004. Annual book of ASTM standards, section 4 (construction), 4.10 (wood).

Akyildiz, M. H., Ates, S., Ozdemir, H. 2009. Technological and chemical properties of heat-treated Anatolian black-pine wood. African Journal of Biotechnology 8: 2565-2572.

Bekhta, P., and Niemz, P. 2003. Effect of high temperature on the change in colour, dimensional stability and mechanical properties of spruce wood. Holforschung. 57: 539-546

Bourgois, J., and Guyonnet, R. 1988. Characterization and analysis of torrified wood. Wood. Sci. Technol. 22: 143-155.

De Groot, W.F., Pan, W.P., Rahman, M.D., and Richards, G.N. 1988. First chemical events in pyrolysis of wood. J. Anal. Appl. Pyrolys. 13: 221-231.

FPInnovations-Forintek, Modified wood and wood-plastic composites substitute for traditional wood products.

http://www.solutionsforwood.ca/_docs/newsletters/straightwoods_new/jan2010/europe_trends.html (accessed January 2010)

Hill, C.A.S. 2006. Wood Modification -Chemical, Thermal and Other Processes, John Wiley and Sons, Chichester, UK

Hingston, J.A., Collins, C.D., Murphy, R.J., and Lester, J.N. 2001. Leaching of chromate copper arsenate wood preservatives: a review. Environ. Pol. 111: 53-66.

Kaas, A., Wangaard, F.F., and Schroeder, H.A. 1970. Chemical degradation of wood: the relationship between strength retention and pentosan content. Wood Fiber 2: 31-39.

Kocaefe, D., Chaudry, B., Poncsáks S., Bouazara, M.., and Pichette, A. 2007. Thermogravimetric study of high temperature treatment of aspen: Effect of treatment parameters on weight loss and mechanical properties. J. Mater. Sci. 42(3): 854-866. 
Kocaefe, D., Poncsák, S., and Boluk, Y. 2008. Effect of thermal treatment on the chemical composition and mechanical properties of birch and aspen. Biores. 3(2): 517-537.

Kocaefe, D., Poncsák, S., Geneviève, D., and Younsi, R. 2008. Effect of heat treatment on the wettability of white ash and soft maple by water. Holz. Roh. Werkst. 66: 355-361.

Kocaefe, Y., Kocaefe, D. (2008). A Method of Thermally Treating Wood”, Patent application in progress. International publication number and date: WO 2008/000081, 3/01/2008. European publication number and date: EP 2040894, 01/04/2009.

Levan, S.L., Ross, R.J., and Winandy, J.E. 1990. Effects of fire retardant chemicals on bending properties of wood at elevated temperatures. Res. Pap. FPL-RP-498.

Mabicka, A., Dumarçay, S., Rouhier, N., Linder, M., Jacquot, J.P., Gérardin, P., and Gelhaye, E. 2005. Synergistic wood preservatives involving EDTA, irganox 1076 and 2-hydroxypyridine-Noxide. Int. Biodeter. Bidegrad. 55: 203-211.

Militz, H. 2002. Heat treatment technologies in Europe: scientific background and technological state of art. Proc. Conference of enhancing the durability of lumber and engeneered wood products. Kissimmee, Orlando, US, February 2002. Forest Product Society, Madison.

Nazerian, M., Ghalehno, M.D., Kashkooli, A.B. 2010. Effect of Wood Species, Amount of Juvenile Wood and Heat Treatment on Mechanical and Physical Properties of Laminated Veneer Lumber. Journal of Applied Science. 11:980-987.

Pizzi, A., Stephanou, A., Boonstra, M.J., and Pendlebury, A.J. 1994. A new concept on the chemical modification of wood by organic anhydrides. Holforschung. 48: 91-94.

Sandland, K.M. 1998. Dimensional stabilization of wood by heat treatment. Proc. Conference of performance of wood. Florence, Italy, May 1998. Mechanical performance of non-standard wood pp.219-227.

Schultz, T.P., and Nicholas, D.D. 2002. Development of environmentally benign preservatives based on the combination of organic biocides with antioxidants and metal chelators. Phytochem. 61: 555-560. 
Seborg, R.M., Tarkow, H., and Stamm, A.J. 1953. Effect of heat upon the dimensional stabilization of wood. J. of FPRS. 3(9): 59-67.

Stamm, A.J. 1964. Wood and Cellulose Science. USA: The Ronald Press Company.

Winandy, J.E., and Lobow, P.K. 2001. Modelling strength loss in wood by chemical composition. Part I. An individual component model for southern pine. Wood. Fib. Sci. 33(2): 239-254.

Winandy, J.E., and Rowell, R.M. 1984. The Chemistry of Solid Wood. Washington: American Chemical Society. 


\section{FIGURE CAPTIONS}

Fig. 1 Impact of (a) maximum treatment temperature, (b) holding time, (c) heating rate, and (d) gas moisture content on MOR of white birch wood. Each point is the mean \pm standard deviation of fourteen different experiments

(NT: untreated sample, H: with moisture in the gas, $\mathrm{WH}$ : without moisture in the gas)

Fig. 2 Impact of (a) maximum treatment temperature, (b) holding time, (c) heating rate, and (d) gas moisture content on MOE of the white birch wood. Each point is the mean \pm standard deviation of fourteen different experiments

(NT: untreated sample, $\mathrm{H}$ : with moisture in the gas, WH: without moisture in the gas)

Fig. 3 Impact of (a) maximum treatment temperature, (b) holding time, (c) heating rate, and (d) gas moisture content on white birch hardness treated in the prototype furnace of UQAC. Each point is the mean \pm standard deviation of fourteen different experiments

(NT: untreated sample, H: with moisture in the gas, WH: without moisture in the gas)

Fig. 4 Percent change in the dimension of thermally-modified and untreated birch wood as a function of (a) maximum treatment temperature, (b) holding time, (c) heating time, and (d) gas moisture content after immersion in water for 24 hours $\left(\% \mathrm{CM}\right.$ at $\left.20^{\circ} \mathrm{C}\right)$

(NT: untreated sample, $\mathrm{H}$ : with moisture in the gas, $\mathrm{WH}$ : without moisture in the gas) 


\section{TABLES}

Table 1 Summary of thermal modification parameters used in the study.

\begin{tabular}{llll}
\hline $\begin{array}{l}\text { Maximum treatment } \\
\text { Temperature }\left({ }^{\circ} \mathrm{C}\right)\end{array}$ & $\begin{array}{l}\text { Heating } \\
\text { rate }\left({ }^{\circ} \mathrm{C} / \mathrm{h}\right)\end{array}$ & $\begin{array}{l}\text { Holding } \\
\text { time }(\mathrm{h})\end{array}$ & $\begin{array}{l}\text { Gas humidity } \\
\text { (g water vapot } / \mathrm{m}^{3} \text { dry gas) }\end{array}$ \\
\hline 195 & 15 & 1 & 100 \\
$205^{4}$ & $15^{\text {a }}$ & $1^{\text {a }}$ & $100^{\text {a }}$ \\
205 & 15 & 3 & 100 \\
205 & 10 & 1 & 100 \\
205 & 15 & 1 & 0 \\
215 & 15 & 1 & 100 \\
\hline
\end{tabular}

${ }^{\text {a }}$ Base conditions 

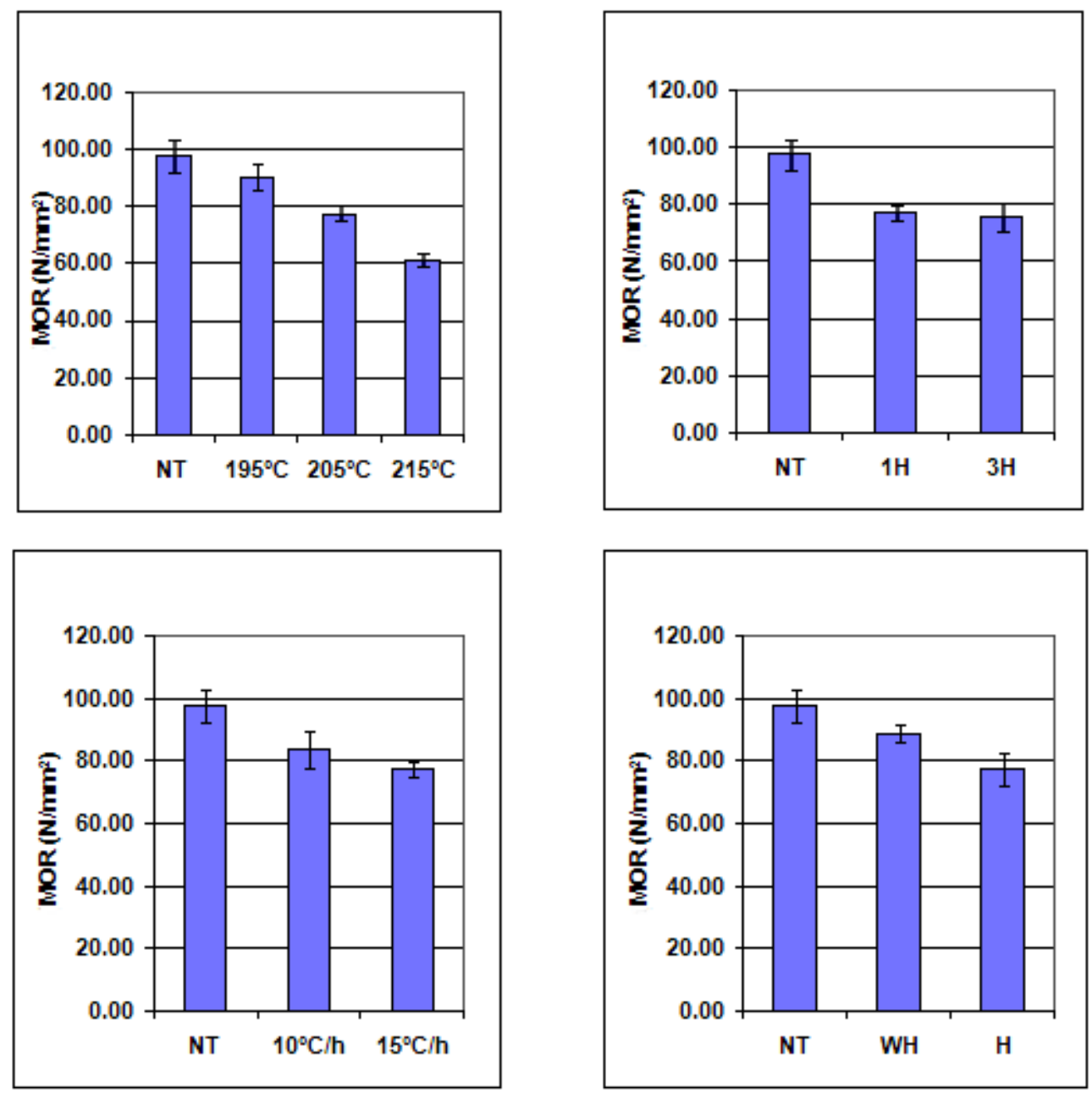

Figure 1 

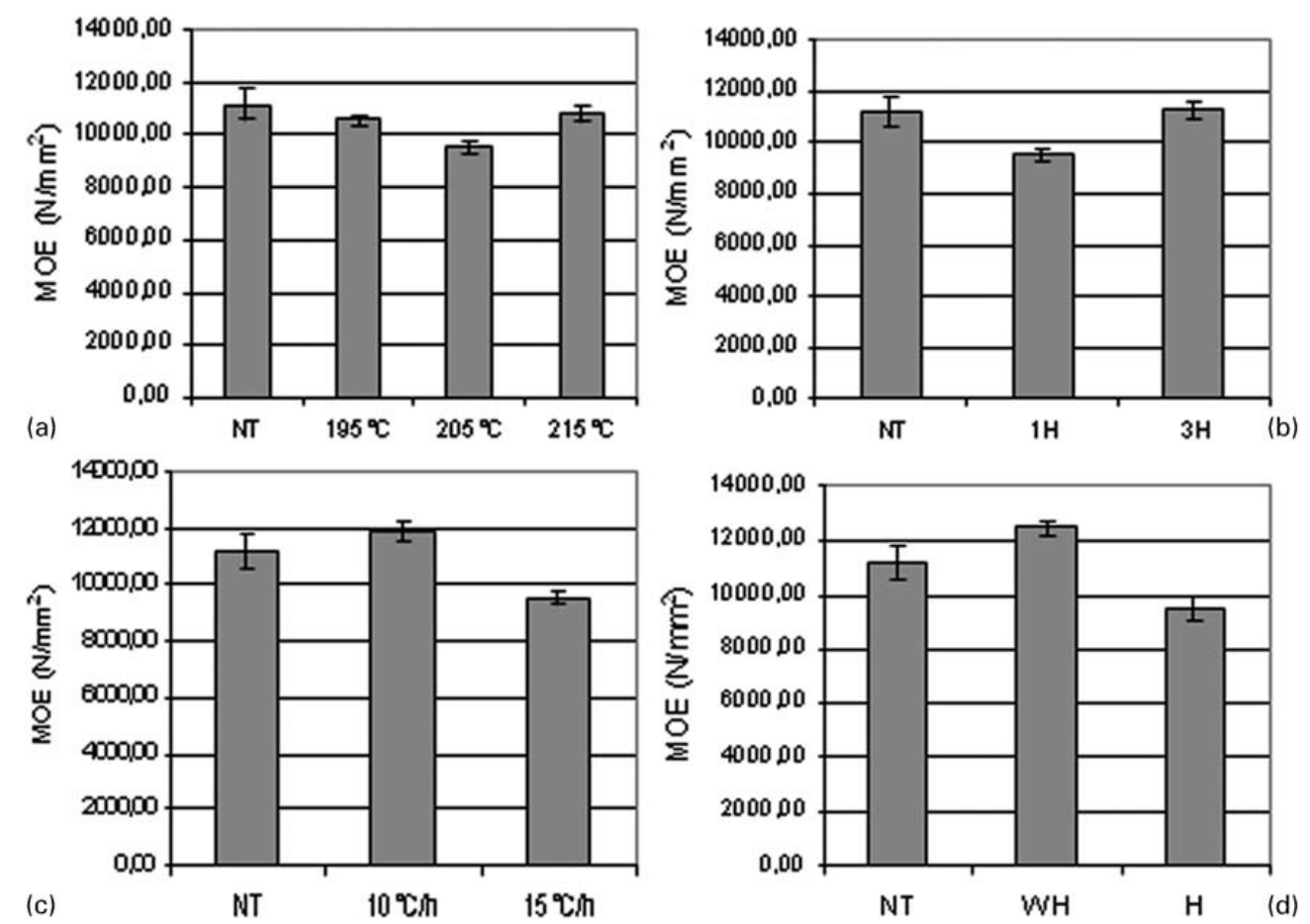

Figure 2 

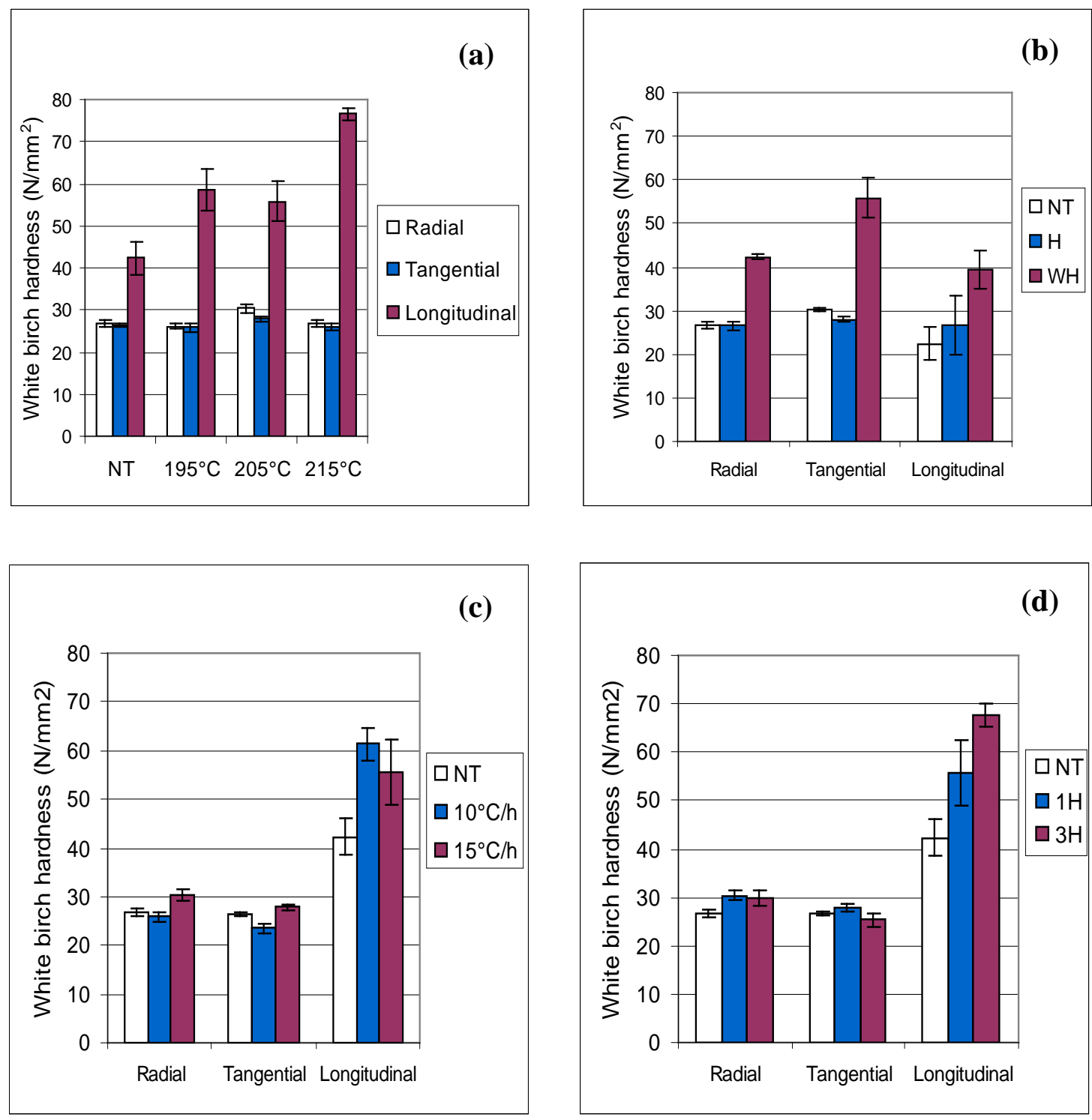

Figure 3 

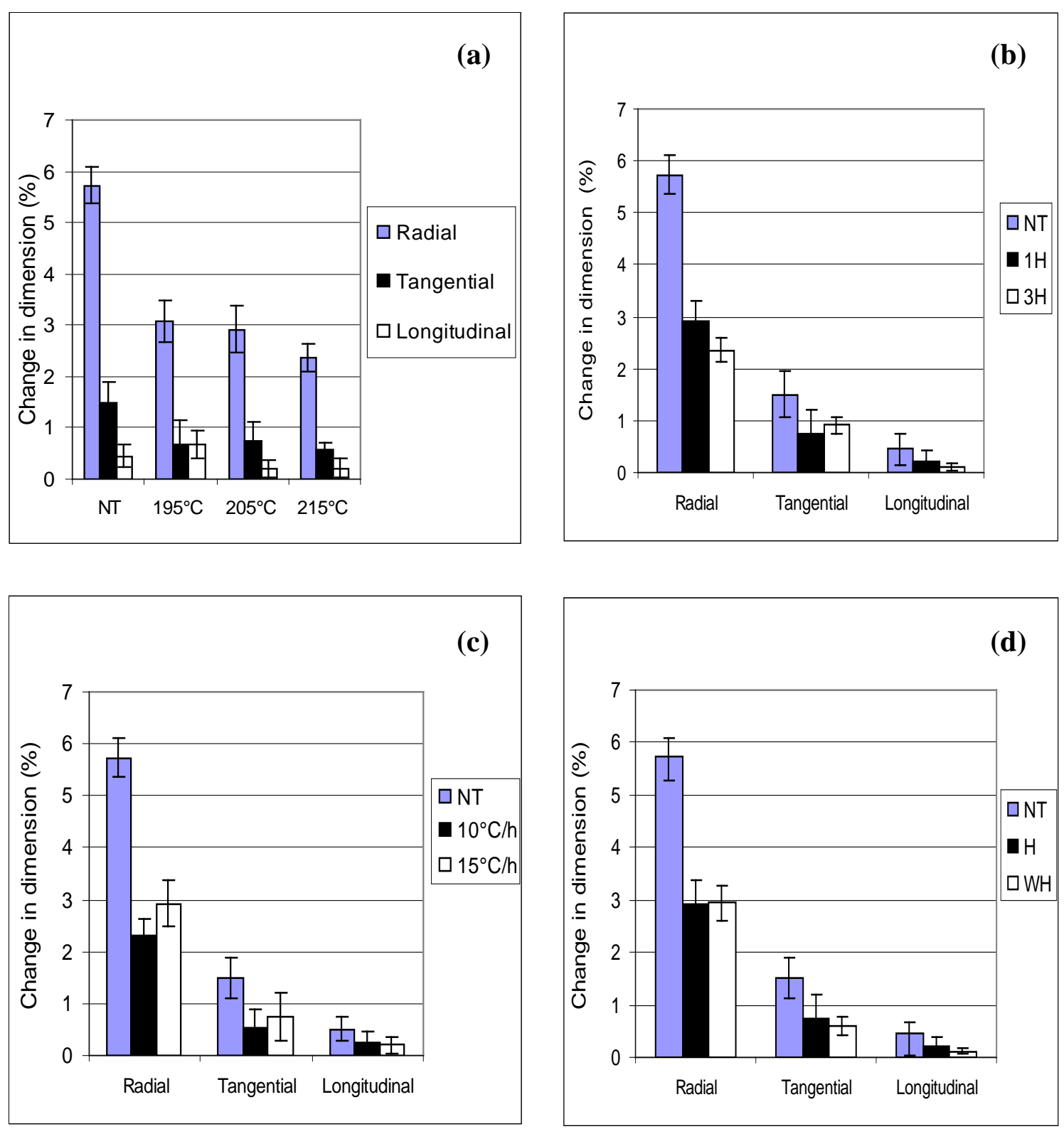

Figure 4 